\title{
Record
}

\section{GENERAL MARTINI}

IT is with great regret that we announce the death, in Germany on 6 January, of General Wolfgang Martini, Executive Director of the Deutsche Gesellschaft für Ortung und Navigation. General Martini, who had a long and distinguished career in telecommunications and radio research, was elected an Honorary Member of this Institute in 1960 ; besides his service decorations he was one of the first officers of the former German Army to be awarded the Grand Service Cross of the Services Order of the Federal Republic of Germany. During the war, General Martini directed the Air Force Signal Corps, which produced the first German radar equipment. After the war, he became Director of the Ausschuss für Funkortung, which later became the Deutsche Gesellschaft für Ortung und Navigation. In this capacity he was responsible for much of the growth in international cooperation on a technical level in navigation, one result of which was the series of meetings sponsored jointly by the German society with this Institute and the French Institute of Navigation.

General Martini combined great intellectual vigour with a remarkably courteous approach, which one somehow knew to be real. It was an engaging mixture, and sometimes an amusing one, because for all his kindness he was not easily deflected. He inspired affection in all who had to do with him, not only in his own country but abroad, and he will be very much missed.

M.W.R.

\section{ADMIRAL OF THE FLEET SIR JOHN CUNNINGHAM}

Admiral of the Fleet Sir John Henry Dacres Cunningham, G.C.B., M.V.O., an Honorary Member of this Institute, died on 14 November 1962. He qualified as a Navigating Officer in 1906, and from then on had a most distinguished career, although seldom in the public eye. He was the first and only Navigating Officer to become First Sea Lord. During the Great War he served in the battleship Russell which was sunk in 1916, followed by appointments to the battle-cruiser Renown, where he was promoted to Commander in 1918 , and Lion, the flagship of the Grand Fleet. In I 9 I 8 he became the first navigator of the Hood and squadron navigator in the battle-cruiser squadron under Admiral Sir Roger Keyes. From 1921-3 he was commander at the Navigation School and then joined the Queen Elizabeth as Master of the Fleet until promoted to Captain in June 1924 .

Throughout his career as an active navigating officer he was always considered to be exceptional in all aspects of his trade, and his promotion to Admiral of the Fleet, coupled with his attainment of the highest appointment in the active service, were ample proof of his many other qualities. He continued to show a great interest in navigation, and particularly in the Navigation and Direction School at H.M.S. Dryad, where he regularly attended the Annual Dinner.

During the late war he seldom came to the public eye, but he had his full share of arduous responsibility. In the Mediterranean he was responsible for the taking of Elba, the Anzio landing, and the invasion of Southern France. His true worth 
was that of the ablest navigator; broad thinking and wise in planning; meticulous and unflustered in execution; and successful in completion.

Lieutenant J. H. D. Cunningham qualified in navigation at H.M.S. Dryad in I 906, soon after the Navigation School was created by Captain H. D. Oliver (now Admiral of the Fleet, an Honorary Member of this Institute, who has just celebrated his 98 th birthday). Captain Oliver's remarks on this student are worth remembering: 'V.G. ability and V.G. in all respects'.

Admiral Cunningham was buried at sea in Spithead from H.M.S. Rhyl.

P.J.W.

\section{SUPERSONIC TRANSPORT SEMINAR}

The Supersonic Transport Seminar which was held at Ann Arbor, Michigan, on the 15 and 16 January, 1963-a joint venture of the American Institute of Navigation and the University of Michigan-was in two parts. The first day a number of lectures were given and on the second day three Discussion Groups were formed, covering :

I. Air Traffic Control;

2. Navaids (Airborne and Ground Systems); and

3. Off-optimum operation (performance).

The first speaker, Robert Shank, Deputy Administrator for Development with the Federal Aviation Agency, covered two main aspects. Firstly, the American reason for going to Mach 3, and secondly the ATC system required for the supersonic. In summary, he implied that aviation in the U.S.A. had become the medium for mass transportation and it was clearly the responsibility of his Department to ensure that the best available aircraft should be provided in line with the essential demands of the travelling public. The decision to go to Mach 3 was not merely because this was the higher speed of the two aircraft types under consideration. The essential point economically was that the life of this aircraft would approach ten years, and this was essential to balance the high cost. It was extremely difficult to see how one could hope to get a similar return from the Mach 2.0 aircraft.

Of the ATC system design required, Mr. Shank implied that what was needed was entirely consistent with the aims of the present administration for current aircraft, but the characteristics of the supersonic would necessitate a tremendous effort to bring about very quickly the improvements necessary. There would appear to be an appreciation in the FAA that a strategic system is required which will enable the aircraft to take-off, to fly direct, and to approach and land without holding and with very little tactical control interference of any kind.

Mr. Shank was followed by Mr. O'Day of the Institute of Science and Technology of the Institute of Michigan, a statistician, who called for a clear understanding of the language used by manufacturers in dealing with accuracy and reliability of systems. He emphasized the need to ascertain operational accuracy; in other words, the 'end product' in the 'working environment'. The lecture was interesting but unlikely to produce any soul searching by manufacturers. The operators' representatives present will be watching more carefully the claims of manufacturers in the future.

Commander C. J. Kelly of the FAA discussed in general terms the likely changes in the characteristics of North Atlantic traffic with the introduction of 